\title{
The Impact of Early Participation in Undergraduate Research Experiences on Multiple Measures of Premed Path Success
}

\author{
Paulette Vincent-Ruz, Joseph Grabowski, Christian D. Schunn,
}

University of Pittsburgh

\begin{abstract}
The authors examine the effects of undergraduate research experiences on key steps in the path to medical school, considering the case of an undergraduate research experience (URE) offered to first-year students that also might influence performance in large introductory science courses. Using a historical dataset of 15,000 first-year students, logistic and linear regressions were performed to better understand the influence of early UREs on different measures of college success. Immediate effects of an early URE on second-year course performance and very large effects on second-year retention are demonstrated. There also are delayed effects on taking the MCAT and medical school acceptance. Results demonstrate the importance of early UREs and their role in STEM student persistence.
\end{abstract}

Keywords: chemistry, early undergraduate research, MCAT, premed, student retention

doi: 10.18833/spur/1/3/12

Is there a relationship between an undergraduate research experience (URE) that takes place in year 1 or year 2 of a four-year course of study and success on the path to medical school? Most advisers of students seeking acceptance in a health sciences graduate program strongly advocate for a significant amount of research experience. UREs are but one part of an undergraduate's experience, and more evidence is generally needed to ascertain the range of URE impacts on students (National Academies of Sciences, Engineering, and Medicine 2017), even though it is generally accepted that participating in a URE positively correlates with a number of student outcomes (Jones, Barlow, and Villarejo 2010; O’Donnell et al. 2015;
Stanford et al. 2015). Impact studies have generally focused on the great majority of undergraduates who experience authentic research as more senior students, particularly summer immersion experiences. More recently, attention has shifted to extending UREs to beginning students and to offering them during the semester, since students are especially likely to struggle before the first summer (Grabowski, Heely, and Brindley 2008; Jones et al. 2010). Further, the effects of an early URE on the large subgroup of premedical students-including how URE participation might counter negative impacts of their large, introductory chemistry classes-are not well understood (Barr et al. 2009).

\section{First Experiences in Research}

At the University of Pittsburgh, First Experiences in Research (FE-R), offered in spring 2004 and every spring since, is designed for first-year students to learn about and contribute to the ongoing research of a faculty member. Each undergraduate is part of a cohort that meets for seven 50-minute workshops during the term and is introduced to aspects of academic research. The primary responsibility of each student is to devote five to ten hours per week to the research project (amounting to one or two credit hours). A prior report on the details of the program, including retention rates, has appeared (Grabowski et al. 2008). Students are recruited during the fall term, prior to acquiring any collegiate GPA. They prepare a resume and are matched by the Office of Undergraduate Research, Scholarship, and Creative Activity (previously the Office of Experiential Learning) to faculty for interviews. Prior to the end of the fall term, faculty members identify the students with whom they will work in the spring. The program continues to be popular among students, with 
enrollments over the last three spring terms (2015-2017) averaging 329 and ranging from 285 to 373. One important aspect of FE- $\mathrm{R}$ is that it is not a summer immersion project but rather a one-term authentic research experience with defined scaffolding.

\section{Methods}

The starting dataset consisted of approximately 17,000 first-year students enrolled in General Chemistry 1 or General Chemistry 2 at some point between 2010 and 2016 at the University of Pittsburgh. Demographics for the sample are found in Table 1. The university provided students' records and grades with identifying information removed so researchers of this project would have no knowledge of students' identities, in compliance with information privacy laws. Provided records included demographics, SAT scores, grades for all university courses, whether students took the MCAT, MCAT scores, and whether they were accepted at a medical school. A total of 1,376 students took the early URE course between 2010 and 2016. There was no access to the contents of the research experience or, most saliently, information on whether the student's research experience was STEM-related. As the study focused on STEM and medical school outcomes, a proxy for the likelihood of STEM research was used: a student who had taken at least two science classes (not including math) by the end of the first year. Eighty-five percent of students completed the early URE course in their first year (used for analyses of effects on the second year), and 15 percent took the course in their second year (included for analyses of end-of-degree outcomes).

\section{Findings and Analysis}

\section{Performance during the Year after an Early URE}

The authors first studied the effects of the early URE on the following year (the course was offered in the spring).
Table 2 presents effects on several steps on the path to medical school that are particularly salient in the second year of the undergraduate degree: whether students re-enroll in the university in the semester following the early URE (for their third semester); the overall GPA of that semester; and performance in one of the most difficult courses of the premed student, Organic Chemistry 1, which is generally taken for the first time in the second year (either the third or fourth semester, so that a student can apply to medical school at the end of the fourth or fifth year of study). Reductions in number $(N)$ in each model result from students with missing predictors (e.g., SAT score). For binary outcomes the models are logistic regressions, and for other outcomes the models are linear regressions. In each case, the model takes into consideration successful completion of the early URE course along with the key personal characteristics covariates generally predictive of these outcomes and therefore possible confounding factors. Model variations that include the full set of available personal characteristics covariates (e.g., high school GPA, parental adjusted gross income, first-generation college status) produced similar results, although with lower $\mathrm{Ns}$ due to higher levels of missing data.

The first regression model shows the effect of taking an early URE on third-semester retention. Results are presented as odds ratios (Szumilas 2010). The odds ratio of an early URE indicates the odds that retention will occur given exposure to an early URE. In comparison to several demographic factors and measurements of academic achievement, undertaking an early URE was the strongest predictor of third-semester retention. McFadden's pseudo R-squared indicated excellent fit of the model (Veall and Zimmermann 1996). Even though most students are likely to be retained into the third semester, students enrolled in an early URE were 2.8 times more likely to be retained

TABLE 1. Student Sample Description

\begin{tabular}{|l|l|c|c|}
\hline Variable & Indicator & N & $\begin{array}{c}\text { Percentage of } \\
\text { students }\end{array}$ \\
\hline \multirow{2}{*}{ Sex } & Female $=1$ & 8,771 & $52 \%$ \\
\hline \multirow{5}{*}{ Ethnicity } & Male $=0$ & 8,227 & $48 \%$ \\
\hline \multirow{5}{*}{ First experience in research } & White $=1$ & 12,068 & $71 \%$ \\
\hline & Asian $=1$ & 2,419 & $14 \%$ \\
\cline { 2 - 4 } & Black = 0 & 1,019 & $6 \%$ \\
\cline { 2 - 4 } & Latinx $=0$ & 579 & $3 \%$ \\
\cline { 2 - 4 } & Other $=0$ & 913 & $6 \%$ \\
\cline { 2 - 4 } & No or not STEM-related = 0 & 13,963 & $6 \%$ \\
\hline
\end{tabular}

14 Scholarship and Practice of Undergraduate Research 
TABLE 2. Immediate Outcomes of Early URE, Linear and Logistic Regression Models

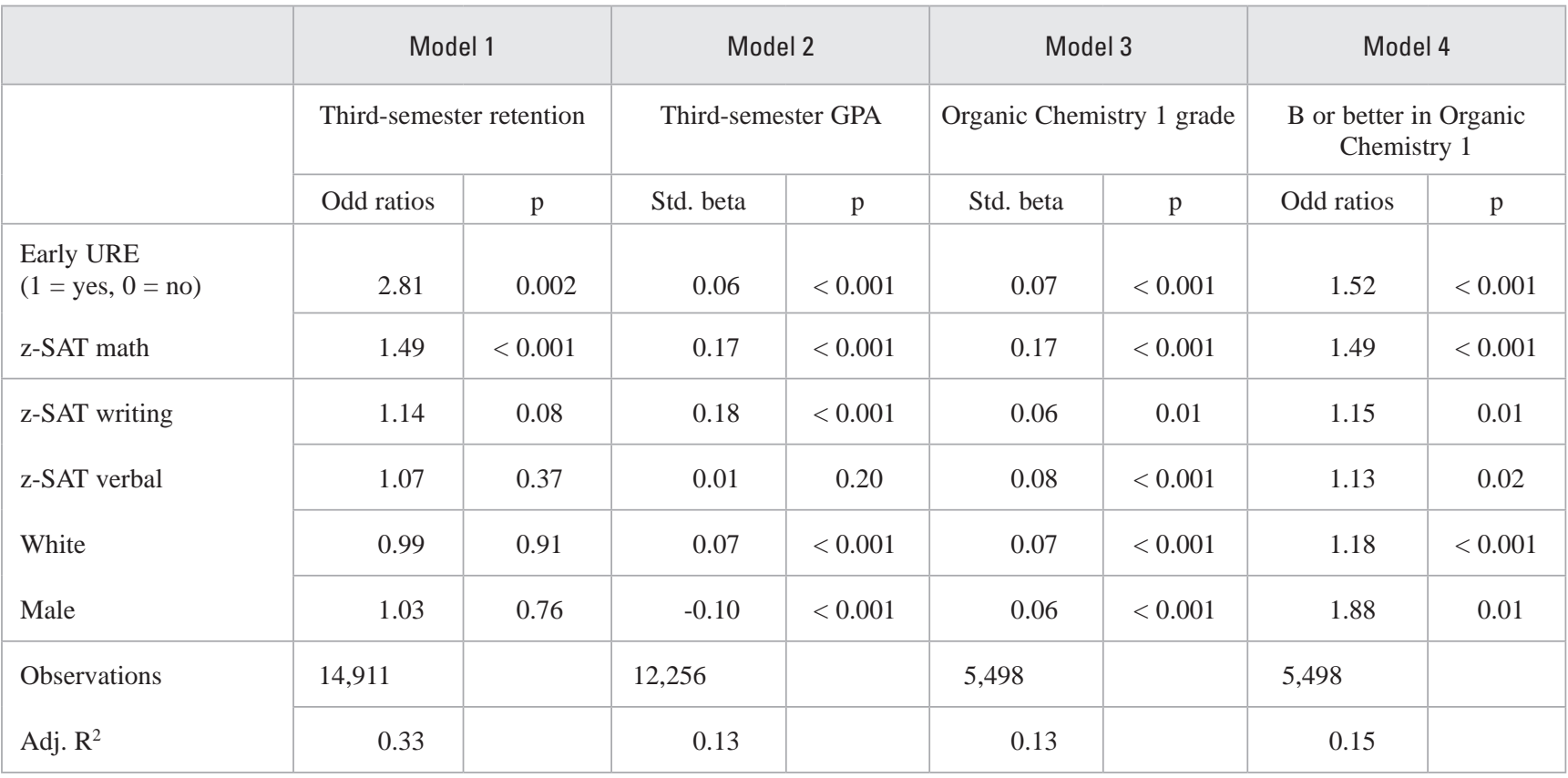

than students who did not have this experience, even after controlling for other preexisting differences. To visualize this relationship, SAT math scores (the largest academic predictor of retention among these STEM-oriented students) were divided into three groups, in which the high and low groups were defined by being more than one standard deviation above or below the sample mean, respectively. Figure 1 shows the relationship between probability of retention into the third semester with or without an early URE for each of the three SAT math levels. The SAT maximum score is 800 , and the national mean is 500 . Thus, even the low group is relatively high compared to national norms, reflecting selection effects of this research-oriented university and the decision to pursue a STEM degree (as shown by early enrollment in science courses). Although there is a relationship in each of the three SAT subgroups, the correlation of early URE with retention is largest at lower SAT math levels; further, retention of the low SAT group with an early URE is similar to retention of the high SAT group without an early URE.

The second model examines the relationship of an early URE with the third-semester GPA, controlling for the same incoming characteristics. Although the model shows a positive and statistically significant relation, the effect is quite small (see Model 2 in Table 2). It may be that the difficulty of courses attempted by students differed, with students who felt less supported choosing to delay or minimize the number of concurrent difficult courses. Some courses, like organic chemistry, are quite challenging, whereas many elective courses and lab courses have high course averages. In addition, quality of teaching and grading curves can affect even sections of a difficult course. The third-semester benefit is found only in students enrolled in a number of difficult courses that semester, and overall the unaccounted-for variance in a specific-semester GPA is likely to be large, further reducing the effect size.

The third and fourth models specifically examine whether an early URE has a positive impact in Organic Chemistry 1 , one of the more challenging courses of the premed track and certainly among courses most commonly taken in the second year. Model 3 in Table 2 shows the regression in overall grade. Here, the SAT math score is the strongest predictor of the Organic Chemistry 1 grade, but there is a small, statistically significant positive effect of an early URE. Since this chemistry course has little quantitative reasoning, this strong relationship may occur because the SAT math score is correlated with other abilities like spatial skills or with self-efficacy in chemistry. Premed students generally need to obtain at least a moderately good grade in Organic Chemistry 1 to do well on the MCAT and to have a high overall science GPA, and Model 4 represents the logistic regression for the probability of earning a B or better in Organic Chemistry 1. Again, the SAT math score is a strong predictor, but the correlation with pursuing an early URE is similar in magnitude. When visualizing the relationship of an early URE across different SAT math levels (see Figure 2), there is a consistent increase in achieving a $\mathrm{B}$ or better at all levels with exposure to an early URE. 
FIGURE 1. Early URE Experience and Probability of Enrolling in Third Semester within SAT Math Subgroups

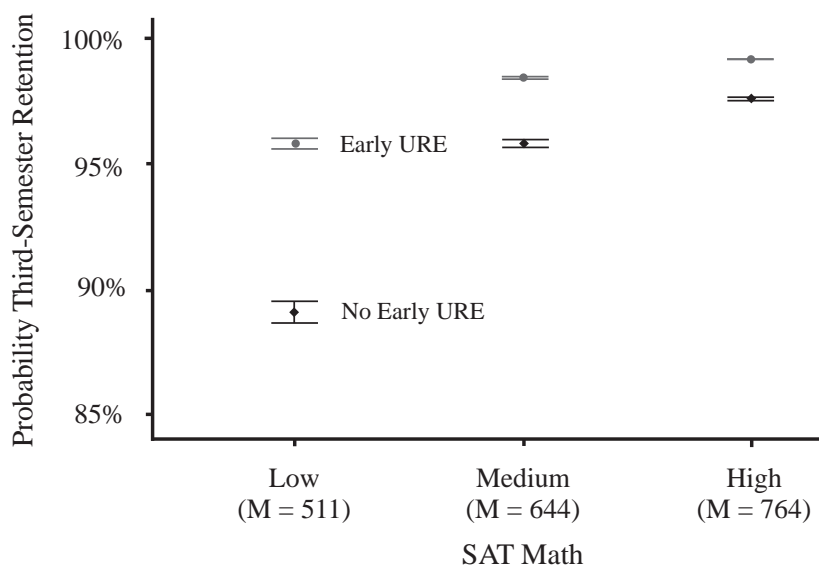

Note: Probabilities noted with standard error bars. Mean scores of each SAT subgroup given in parentheses.

FIGURE 2. Early URE Experience and Probability of Obtaining a B or Better in Organic Chemistry 1 within SAT Math Subgroups

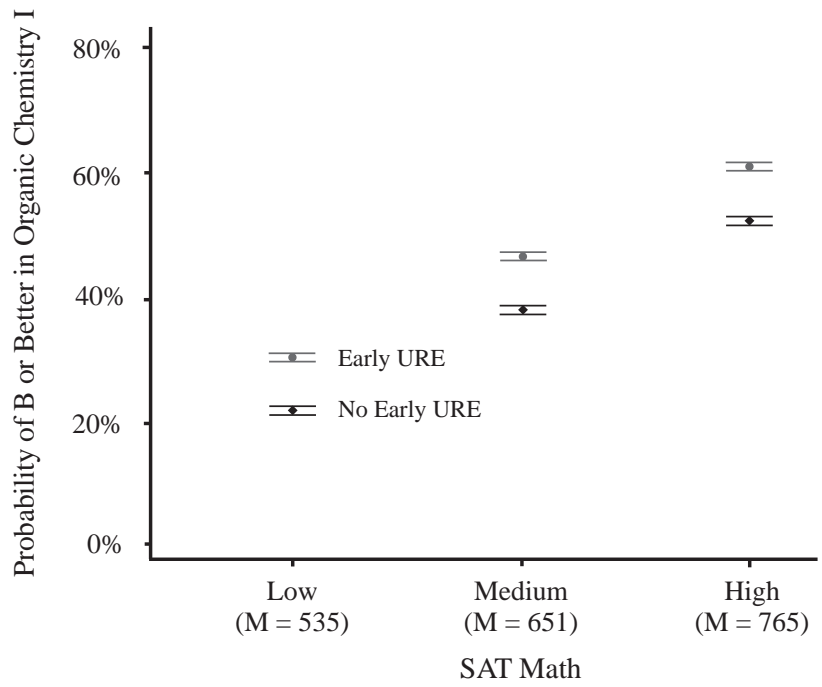

Note: Probabilities are noted with standard error bars. Mean scores of each SAT subgroup are given in parentheses.

\section{Relationship to the MCAT and Admission to Medical School}

To examine the correlation between an early URE and eventual admission into medical school, students were assigned a URE variable of 1 if they had enrolled in the course in either the first or second year and a 0 otherwise (approximately 15 percent of students taking the course did so in their second year of enrollment). Students who participate in an early URE are almost three times more likely to take the MCAT test than those who do not (see Model 5 in Table 3). However, having the early URE is not a significant predictor of MCAT scores (see Model 6 in Table 3) when including the demographic and academic ability covariates. It may be that those students with lower science GPAs simply drop off the pathway, and there is no remaining effect of those who take the MCAT, or perhaps later studying for the MCAT overwhelms the previous (small) benefits of an early URE for difficult courses like organic chemistry.

Model 7 examines the relationship between an early URE and acceptance into medical school. Since MCAT scores are nonlinear predictors of medical school acceptance (Albanese et al. 2003), MCAT scores were organized into three groups, using thresholds of one standard deviation above and below the national mean. SAT scores are not included in Model 7 for both statistical (colinearity with MCAT scores) and conceptual (inclusion of overall academic ability factors in MCAT scores) reasons. As Model 7 in Table 3 shows, there is an 85-percent increase in likelihood of admission to medical school for those with the early URE. Figure 3 shows the correlation between having an early URE and being accepted into medical school across all three MCAT levels. The early URE effect is largest for students with average MCAT scores.

\section{Conclusions}

This article makes two important contributions to the literature. First, the authors demonstrate substantial immediate effects of an early URE, especially on second-year retention but also for success in the very challenging Organic Chemistry 1 course. Effects are especially large for students with lower SAT scores. Second, delayed effects of an early URE are found for last-step premed students: students who participate in an early URE have a significantly greater chance of being accepted when they have an MCAT score close to the national average. This has important equity implications. By allowing wider and more equitable student access to this type of early experience, institutions can diversify the medical school applicant pool and accepted cohorts.

Allowing a larger group of students to take part in early URE is of interest in any context in which training is funneled through a fixed limited-capacity gate, which occurs in many areas of education (e.g., positions at selective universities, in selective postgraduate programs, and in competitive professional contexts). Increasing access has an important impact at the systems level. Although the total number of students admitted to medical school will not change, reordering of admitted students may be important to the system. It is highly unlikely that the current educational system does an optimal job of providing equal opportunities. The research literature has documented in great detail how skin color, parental income, parental education, and geographic location influence educational opportunities. More specific to the current topic, students attending highly selective private universities have more 
TABLE 3. URE Relationship with Taking the MCAT, MCAT Score, and Medical School Acceptance, Linear and Logistic Regressions

\begin{tabular}{|c|c|c|c|c|c|c|}
\hline & \multicolumn{2}{|c|}{ Model 5} & \multicolumn{2}{|c|}{ Model 6} & \multicolumn{2}{|c|}{ Model 7} \\
\hline & \multicolumn{2}{|c|}{$\begin{array}{l}\text { Likelihood of } \\
\text { taking the MCAT }\end{array}$} & \multicolumn{2}{|c|}{ MCAT score } & \multicolumn{2}{|c|}{$\begin{array}{l}\text { Acceptance into } \\
\text { medical school }\end{array}$} \\
\hline & Odd ratios & $\mathrm{p}$ & Std. beta & $\mathrm{p}$ & Odd ratios & $\mathrm{p}$ \\
\hline Early URE $(1=$ yes, $0=$ no $)$ & 2.92 & $<0.001$ & 0.02 & 0.53 & 1.85 & 0.05 \\
\hline z-SAT math & 1.74 & $<0.001$ & 0.21 & $<0.001$ & & \\
\hline High MCAT score & & & & & 6.11 & $<0.001$ \\
\hline Low MCAT score & & & & & 0.02 & $<0.001$ \\
\hline z-SAT writing & 1.66 & $<0.001$ & -0.10 & 0.20 & & \\
\hline z-SAT verbal & 0.89 & 0.17 & 0.45 & $<0.001$ & & \\
\hline White & 0.55 & $<0.001$ & 0.10 & 0.05 & 0.42 & 0.03 \\
\hline Male & 1.46 & $<0.001$ & 0.20 & $<0.001$ & 0.18 & 0.01 \\
\hline Observations & 9.327 & & 533 & & 533 & \\
\hline Adj. $R^{2}$ & 0.14 & & 0.33 & & 0.21 & \\
\hline
\end{tabular}

FIGURE 3. Early URE Experience and Probability of Acceptance into Medical School within MCAT Subgroups

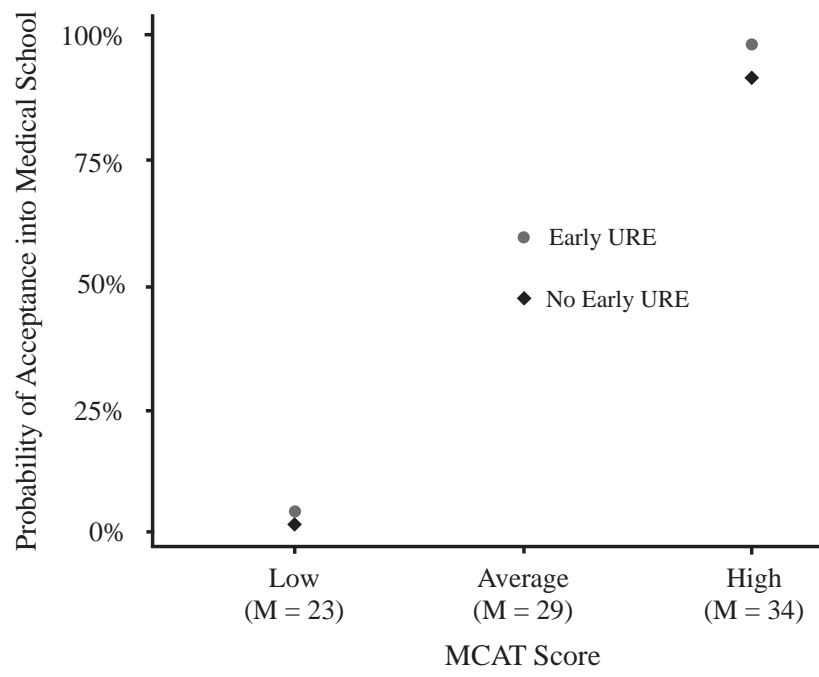

Note: Mean scores of each MCAT subgroup are given in parentheses.

access to undergraduate research opportunities (simply by the ratio of undergraduates to research-active faculty), making them more likely to gain acceptance to medical school. Therefore, these findings have overall equity implications. For universities with fewer resources to invest wisely in relevant educational experiences (such as undergraduate research experiences), there is a need for evidence that the financial and logistical costs are outweighed by the benefits for students. It is hoped that this report will lead higher education institutions and administrators to make these opportunities more available and equitable.

Although the analyses presented here are correlational in nature, they did control for student characteristics that are strongly predictive of success. Nonetheless, the addition of experimental or quasi-experimental evidence would supplement the current findings. This report also leads to a further series of questions to be addressed in future work. Do early URE participants complete more URE in total than students who participate in URE in year 3 or year 4 ? How do URE effects change by demographic factors such as gender and race?

\section{References}

Albanese, Mark A., Mikel H. Snow, Susan E. Skochelak, Kathryn N. Huggett, and Philip M.Farrell. 2003. "Assessing Personal Qualities in Medical School Admissions." Academic Medicine 78: 313-321. doi: 10.1097/00001888-200303000-00016

Barr, Donald A., John Matsui, Stanley F. Wanat, and Maria E. Gonzalez. 2009. "Chemistry Courses as the Turning Point for Premedical Students." Advances in Health Sciences Education 15: 45-54. doi: 10.1007/s10459-009-9165-3

Grabowski, Joseph J., Margaret E. Heely, and Jacob A. Brindley. 2008. "Scaffolding Faculty-Mentored Authentic Research Experiences for First-Year Students." CUR Quarterly 29(1): 41-47. 
Jones, Melanie T., Amy E. L. Barlow, and Merna Villarejo. 2010. "Importance of Undergraduate Research for Minority Persistence and Achievement in Biology." Journal of Higher Education 81: 82-115. doi: 10.1353/jhe.0.0082

National Academies of Sciences, Engineering, and Medicine. 2017. Undergraduate Research Experiences for STEM Students. Eds. James Gentile, Kerry Brenner, and Amy Stephens. Washington, DC: National Academies Press. doi: 10.17226/24622

O’Donnell, Ken, Judy Botelho, Jessica Brown, Gerardo M. González, and William Head. 2015. "Undergraduate Research and Its Impact on Student Success for Underrepresented Students." New Directions for Higher Education 2015(169): 27-38. doi: $10.1002 /$ he. 20120

Stanford, Jennifer S., Suzanne E. Rocheleau, Kevin P. W. Smith, and Jaya Mohan. 2015. "Early Undergraduate Research Experiences Lead to Similar Learning Gains for STEM and Non-STEM Undergraduates." Studies in Higher Education 42: 115-129. doi: 10.1080/03075079.2015.1035248

Szumilas, Magdalena. 2010. "Explaining Odds Ratios." Journal of the Canadian Academy of Child and Adolescent Psychiatry 19: 227-229.

Veall, Michael R., and Klaus F. Zimmermann. 1996. "PseudoR2 Measures for Some Common Limited Dependent Variable Models." Journal of Economic Surveys 10: 241-259. doi: 10.1111/j.1467-6419.1996.tb00013

\section{Paulette Vincent-Ruz}

University of Pittsburgh, pvincentruz@pitt.edu

Paulette Vincent-Ruz is a PhD student in learning sciences and policy at the University of Pittsburgh. Her research focuses on the malleable factors that increase participation in science for marginalized populations, with a specific focus on young women.

Joseph J. Grabowski is a professor in the Department of Chemistry at the University of Pittsburgh. He also serves in a part-time capacity as the director of undergraduate research for arts and sciences. He is involved in K-12 science education in Pittsburgh, including curriculum design for the Pittsburgh Science and Technology Academy, which serves high school students. In addition, he has active research programs in photoacoustic calorimetric measurements of reactive molecules, applications of gas-phase ion-molecule methods for trace gas analysis, and creation of unique resources for modern chemical education.

Christian Schunn is co-director of the Institute for Learning; senior scientist at the Learning Research and Development Center; and professor of psychology, learning sciences and policy, and intelligent systems at the University of Pittsburgh. He directs a number of research and design projects in science, mathematics, and engineering education. This work includes studying expert engineering and science teams, building innovative technology-supported STEM curricula, and studying factors that influence learning and engagement of students and teachers. He is a Fellow of the American Association for the Advancement of Science, the International Society for Design and Development in Education, and the American Psychological Association. 